\title{
O DIÁLOGO SOBRE O ENSINO RELIGIOSONA HISTÓRIA DA IGREJA DO BRASIL
}

\section{The dialogue on religious teaching in the history of the church of Brazil}

Sérgio Rogério Junqueira ${ }^{1}$

Terezinha Sueli Rocha ${ }^{2}$

\section{RESUMO}

Este artigo é um segundo relatório resultante do Programa de pesquisa Concepções e recursos do Ensino Religioso no Projeto Concepção e Produção visando compreender este componente curricular no cenário brasileiro e verificar a inserção da Igreja Católica Apostólica Romana no contexto escolar nacional. Este é um artigo resultante da pesquisa qualitativa e documental que explicita a contribuição Católica por meio da Conferência Nacional dos Bispos do Brasil (CNBB) para a configuração desta disciplina em instituições de ensino. Para tal, foram utilizados documentos e textos desta instituição eclesial e da história da educação para articular este percurso histórico.

Palavras-chave: História da educação; ensino religioso; Igreja Católica

\begin{abstract}
This article is a second report resulting from the research Program Conceptions and Resources of Religious Education in the Conception and Production Project, aiming to understand this curricular component in the Brazilian scenario and verify the insertion of the Roman Catholic Church in the national school context. This is an article resulting from qualitative and documentary research that explains the Catholic contribution through the National Conference of Brazilian Bishops (CNBB) to the configuration of this discipline in educational institutions. To this end, documents and texts from this ecclesial institution and from the history of education were used to articulate this historical path.
\end{abstract}

Keywords: History of education; religious education; Catholic Church.

\section{Introdução}

O processo educativo que envolve a curiosidade, descoberta e significação não é ato solitário, se dá no coletivo e por isso deve ser construído a muitas mãos, e isso também é perceptível na ação de algumas instituições.

Na história brasileira é inegável a contribuição substancial da Igreja Católica Apostólica Romana (ICAR) para a área educacional, que por vezes teve modificada sua forma de atuação, em algumas situações tendo em vista as orientações da Santa Sé e em tantas outras ao levar em

\footnotetext{
${ }^{1}$ Pós-Doutor em Ciência da Religião (PUCSP-UEPA) e Geografia da Religião (UFPR). Doutor e Mestre em Ciência da Educação (UPS-Roma). Licenciado em Pedagogia (UNIUB). Bacharel em Ciências Religiosas (IMACH). Livre Docente em Ciência da Religião (PUCSP). E-mail: srjunq@gmail.com

${ }_{2}$ Mestre em Teologia (PUC-PR). Graduada em Pedagogia (PUC-PR). Pesquisadora do IPFER. E-mail: terezinhasuelirocha@yahoo.com.br
} 
conta as transformações da sociedade, e das leis que a regem, leis da Igreja e do Estado brasileiro.

No meio educacional dentre as muitas áreas sobre as quais a ICAR mantém influência destaca-se de forma especial o Ensino Religioso, a fim de possibilitar uma reflexão sobre a contribuição dada pela ICAR, com relação a esse componente curricular.

Dentro da realidade de que o ensinar está ligado intimamente com a proposta de sociedade, sendo justa e participativa, o ser humano, como um ser integral, que se acredita, e o Ensino Religioso participando deste projeto, foi empreendida a reflexão com relação às instruções e posicionamentos da Conferência Nacional dos Bispos do Brasil (CNBB) nos documentos gerados por ela.

Refletir sobre as ações empreendidas pela CNBB com relação a formação em geral, e em especial aquelas ligadas a religiosidade dentro da esfera educacional, já que é quesito importante para a formação da sociedade, se faz mister, pois contribui sobremaneira para o desenvolvimento do ser humano e o aprimoramento de suas capacidades. A Conferência contribuiu na formação integral e no exercício da cidadania, por suas ações pautadas no respeito com o diferente e na superação das injustiças encontradas no mundo. (JUNQUEIRA, WAGNER, 2011)

A CNBB reúne importantes ligações no universo religioso e acompanha o desafio dos profissionais da educação em geral, e em especial para professores, alunos e suas famílias, sendo necessário distanciamento para analisar as variáveis educativas que forneceu e têm fornecido como, importantes, subsídios para a evolução da disciplina. A reflexão e compreensão da dinâmica da escolarização se basearam em seus pronunciamentos e publicações.

Desenvolver esta temática, de forma responsável, indicou a necessidade de refazer um levantamento histórico, já empreendido em outras oportunidades, para tornar possível vislumbrar ações desde as primeiras experiências no campo de uma catequese de conversão, perpassando pelo início da separação entre Igreja e Estado, até vislumbrar à atual configuração do Ensino Religioso enquanto componente curricular consolidado.

Assim tendo em vista a importante contribuição que o empreendimento indicava foi utilizada metodologia da área da História, com um olhar analítico-crítico, partindo das fontes já citadas, a saber, os textos produzidos pela Conferência Nacional dos Bispos do Brasil: diretrizes gerais, documentos, planos bienais, planos de evangelização, pronunciamentos, e arquivos do Setor de Ensino Religioso da CNBB, além de alguns pronunciamentos de sua 
autoridade máxima, onde se procurou ler o constructo da presença do Ensino Religioso, e sua diversidade de nuances.

A metodologia utilizada na pesquisa, a saber, histórico-analítica, foi embasada nos caminhos oferecidos por Marc Bloch,1982 ao indicar os meios necessários para entender as ações e encaminhamentos dos homens no tempo. A reflexão histórica, pela ótica de Bloch, propicia alinhar tanto a problematização atual com o contexto histórico no qual ela se dá, de forma que o objeto da pesquisa não é propriamente o passado, mas as relações advindas deste.

Entende-se que o objeto pesquisado, neste caso, materiais divulgados pela ICAR, por meio da CNBB, não está solto no tempo e no espaço. Tendo em vista os posicionamentos, ações e atividades da comunidade eclesial, foi buscado por meio da pesquisa histórica-analítica a apreensão do conhecimento pesquisado, fundamentando na existência de "uma relação dinâmica entre o mundo real e o sujeito, uma interdependência viva entre o sujeito e o objeto, um vínculo indissociável entre o mundo objetivo e a subjetividade do sujeito" que é um pressuposto da pesquisa qualitativa (CHIZZOTTI, p.79, 2003).

Com a estruturação, o texto parte da análise sobre a Igreja na Colônia, a Igreja no Império, a Igreja na República, fazendo um paralelo com a história da educação religiosa no Brasil.

\section{A Igreja na colônia}

A história da Igreja no Brasil tem seu início nos anos em que começaram as jornadas de Portugal, nas quais faziam parte alguns representantes da Igreja Católica Apostólica Romana. A Instituição que reúne presença religiosa, cultural, social e política, chega ao Brasil em 1500 e cria raízes nessa sociedade a partir da colonização, iniciada em 1549. Sob a responsabilidade do Frei Henrique de Coimbra realizou-se a celebração dos ofícios religiosos durante a trajetória da viagem e também a escolha de Nossa Senhora da Esperança, como padroeira e protetora da viagem selaram essa relação. E em 26 de abril de 1500, mais um evento importante para demonstrar a relação entre o Estado e a ICAR foi a celebração da primeira liturgia católica em terras brasileiras.

Havia certamente desde aquela época, o desejo de transmitir uma cultura religiosa para os povos ali encontrados. A carta de Pero Vaz de Caminha registra essa realidade: "Quanto mais, disposição para se nela cumprir e fazer o que Vossa Alteza tanto deseja, a saber, acrescentamento da nossa fé!" (Carta de Caminha a El Rei D. Manuel) E assim foi acontecendo o serviço dos religiosos realizando a organização de paróquias e colégios, com a finalidade de 
evangelizar e educar os povos indígenas, e os filhos dos colonos, sendo que se evangelizava os primeiros e educava os segundos, promovendo a cristianização e a ocidentalização da população. Nessa tarefa envolvendo congregações e ordens religiosas houve a estruturação educacional no país, o que consolidou o projeto de união entre Coroa e Igreja uma realidade e o catolicismo a religião oficial do Brasil.

Essa relação entre Estado e ICAR perdurou até a segunda metade do século XIX, envolvendo privilégios e controle de atividades atreladas entre Portugal, Espanha e Brasil. A força da cruz e da espada foram ferramentas usadas para influenciar os habitantes locais na adesão aos ensinamentos, fazendo-os crer que a felicidade e a salvação viriam somente por essa integração. (FONAPER, 1998) O contexto histórico do Brasil, na época tinha como condição ser católico para poder ser cidadão brasileiro e esse processo se entrelaçou com interesses de base ideológica na conquista e colonização de novas terras.

Os religiosos conseguiram adaptar-se às exigências políticas e sociais fazendo-se presentes nos ambientes orientando os habitantes na vivência da fé. Os Jesuítas iniciaram a educação formal no Brasil e os Franciscanos, os Capuchinhos e outros religiosos, vieram para evangelizar as novas terras. Também existiram opções de diversas áreas de aprendizado, todas ofertadas pelos religiosos que ali se instalaram e procuraram iniciar os povos nas mais diferentes atividades, inclusive atividades profissionais agrícolas.

A ideia era de que a sociedade deveria corresponder uma única religião e assim aconteceu a troca de favores e privilégios: "o reconhecimento da religião católica como religião oficial e a Igreja cede à monarquia o poder de nomear cargos eclesiásticos e controlar fiscalizando iniciativas da própria instituição religiosa." (MATOS, 1996, 46-47) Nessa troca de favores, houve o empobrecimento da missão evangelizadora que se sujeitou aos caprichos e exigências do Estado, o padroado durou o período imperial. O registro de batismo e casamentos, bem como o controle de cemitérios era da igreja.

A cada situação em que apareciam impasses relativos às crenças e práticas religiosas, vinham também as desconfianças. "Quando surgiam discordâncias de crenças e práticas religiosas, estas eram tratadas como formas perigosas para a religião dominante, sendo, por isso mesmo, proscrita e seus praticantes perseguidos.” (STEIL, 1996, p.48-49) Essa situação perdurou até o Marquês de Pombal mudar a dinâmica tornando a escola dentro dos interesses do Estado e não mais servisse aos interesses da fé. Essa realidade não se alterou com a expulsão dos jesuítas, houve somente a transferência de mãos, de jesuítas para religiosos de outras 
congregações, párocos e outras pessoas nas aulas regias, todas formadas pela concepção jesuíta de educação.

$\mathrm{O}$ catolicismo que chegou ao Brasil junto com os portugueses foi adquirindo características míticas e pagãs pela influência das religiões africanas e indígenas marcadamente mágico-animistas o que caracteriza a concepção do povo em sua pluralidade. Aos poucos foram aparecendo grupos fortes de inspiração cristã, combinando práticas religiosas de diferentes religiões. Essa nova dinâmica abriu espaço para o nascimento do sincretismo religioso enriquecendo a formação, a cultura e os costumes da população, porém sempre com a interferência da cultura vinda da Europa, principalmente através de ações educacionais. Tudo isso foi muito combatido por aqui.

Dentro dessa realidade o Ensino Religioso entra com presença decisiva na discussão sobre pluralismo religioso, sentindo a necessidade de esta disciplina fazer parte da história do Brasil. A segunda constituição da republica retorna o ensino religioso para dentro da escola e nesse período apesar da nomenclatura era ensino da religião católica e tinha o como modelo a catequese.

A ampla articulação entre os Estados expressando e valorizando o direito de manifestação do fenômeno e diversidade cultural foi o ponto chave para que os segmentos culturais tivessem "suas instituições escolares regularizadas, gozando de certa independência de operacionalizar suas propostas, assim como a própria Igreja Católica, o novo referencial, entretanto, é que o Estado assume a educação como uma questão política.” (NEMI, 1996, p. 16)

A cada século vivido no Brasil, a situação vai se transformando e ganhando corpo com mudanças na política influenciando a postura religiosa e cultural da nação. Todas as posturas assumidas trazem repercussões, que mais cedo ou mais tarde, irão influenciar a nação e nessas mudanças a sociedade como um todo se transforma, e a educação como parte integrante da sociedade, também sofre as consequências dessas transformações. No Brasil, a Igreja procurou viver a missão Religiosa e também se inseriu em questões políticas, assumindo muitas vezes o papel que cabia ao Estado. Hoje essa primazia encontra-se na mão de grupos cristãos.

\section{A Igreja no Império}

O Século XIX chegou com a instituição do Império brasileiro e a consequente emancipação da Coroa Portuguesa. A ICAR e continuou como no Brasil Colônia com as nomeações do Episcopado e cargos eclesiásticos, agora cabendo ao Imperador, que acumulava também a 
responsabilidade sobre a manutenção dos mesmos. Havia um controle sobre as pessoas e a profissão da fé católica era exigida até dos professores que ensinavam nas escolas oficiais. A Constituição Imperial de 1824 mostra claramente a situação em que as atribuições do Imperador, Chefe do poder Executivo, que nomeia bispos, magistrados, além de prover benefícios eclesiásticos.

No Art. $5^{\circ}$ da Constituição: “A Religião Católica Apostólica Romana continuará a ser a religião do Império. Todas as outras religiões serão permitidas com seu culto doméstico, ou particular, em casas para isso destinadas, sem forma alguma exterior de templo." (BONAVIDES, Textos Políticos da História do Brasil, Vol. I, Brasília, Senado Federal, 1996, 142)

No ano de 1840, com a nomeação do Imperador Constitucional e Perpétuo Defensor do Brasil, D. Pedro II as relações começaram a mudar e em 1841 os Jesuítas que haviam sido expulsos, receberam autorização para voltar ao país e retomar a Educação. A Igreja no Brasil, durante o Império, assumiu o posicionamento de Pio IX na Encíclica Quanta Cura de 1864, o que desencadeou um conflito religioso por haver questionamento à modernidade e à Ciência. Foram decretadas, nas décadas de 1860 até 1870, algumas regras muito rígidas da doutrina e do culto. E em 1875 o governo, por ter ligação com a maçonaria condenou à prisão os bispos: Dom Macedo Costa, Dom Vital de Oliveira, pelo fato destes terem acatado as novas diretrizes e expulsando os maçons das irmandades.

Nesse processo houve perda de poderes na Igreja, porém esses acontecimentos foram um marco histórico para o Episcopado brasileiro, pois a Igreja passou a ser independente do Estado e resgatou sua identidade, autonomia e viu novas possibilidades de evangelização seguindo as orientações da Santa Sé, e principalmente, "em consequência das reformas do Concílio Vaticano I (1869-1870), com a romanização do clero brasileiro.” (NERY, 1993, p.88)

A Lei de 15 de outubro de 1827 orienta para a estruturação de uma escola de primeiras letras e em relação ao ensino da religião e regulamentando o inciso XXXII do Art. 179 da Constituição Imperial. Art. 6 "Os professores ensinarão a ler, escrever, as quatro operações, [...] e os princípios de moral christã e da doutrina da religião catholica e apostólica romana, proporcionados a compreensão dos meninos;" (BONAVIDES, Textos Políticos da História do Brasil, Vol. IX, Brasília, Senado Federal, 1996, 286). 


\section{A Igreja na República}

Em 15 de novembro de 1889 com a proclamação de uma República no Brasil o Estado Republicano rompeu sua ligação com a Igreja e proclamou seu posicionamento laico, que precisa ser visto a luz de duas correntes: a de Americana e a francesa. O posicionamento que foi oficializado com o Decreto 119-A, de 17 de janeiro 1890 e sua confirmação se deu pela Constituição Republicana de 1891. "Entre as conseqüências da nova postura está a introdução da obrigatoriedade do ensino leigo nas escolas públicas." (JESUS, p.68-78, 1993) Começa aqui uma resistência em relação à fé católica. A reação do Episcopado se manifestou com a Carta Pastoral Coletiva de 19 de março de 1890.

A Proclamação da República trouxe novas possibilidades para as religiões afrobrasileiras, os protestantes e os judeus que até então somente eram reconhecidos, porém era proibida sua manifestação pública nas crenças e práticas. Seus direitos sociais e políticos eram restritos. Novas estruturas de poder foram sendo estabelecidas nesse novo regime político e econômico, a partir da proclamação da República.

Ruy Barbosa quando elaborou o texto da Constituição Brasileira de 1891 seguiu a proposta da Igreja livre e no Estado livre. A escrita da constituição brasileira excluiu do programa escolar o ensino da religião. (BARBOSA, 1965) A posição de Rui Barbosa é a posição de laicidade americana.

Infelizmente, ao contrário do preceito de Rui Barboza, foi a neutralidade escolar que ganhou espaço e não o princípio de liberdade religiosa, o que se tornou na ausência de informação religiosa. O ensino leigo que está presente na Constituição acabou sendo entendido como "irreligioso, ateu, laicista, sem a presença de elementos oriundos das crenças dos cidadãos que freqüentassem as escolas mantidas pelo sistema estatal.” (FIGUEIREDO, 1995, p.45-53) A presença do Transcendente acaba sendo negada nesta visão laicista que assume o ateísmo.

Já a visão laical diz que o Estado não assume uma confissão, mas da liberdade aos seus cidadãos para professarem sua fé, suas crenças e garante para a população a liberdade religiosa. Este processo permite ao Estado brasileiro legitimar-se sem o apelo à religião, e assim o pluralismo religioso afirma-se dentro de uma unidade nacional. O Estado laico promoveu o valor da liberdade religiosa, associada aos direitos individuais que permitem ao povo viver a cidadania. Assim, não era mais necessária uma única religião e surgiu uma variedade de religiões e tornou-se questão pessoal a definição de qual a sua opção por uma ou outra entre todas as possibilidades. 
Pelo fato da população brasileira ser na sua maioria católica a hierarquia eclesiástica buscava uma "influência nas orientações políticas do país, como havia possuído anteriormente. É interessante recordar que, nessa época, o episcopado encontrava-se dispersivo e tumultuado por falta de uma articulação nacional.” (LUSTOSA, 1991, p.46-61) E assim a Igreja aceitou, "o novo regime e, de certo modo, tirou proveito dele. A separação oficial do Estado permitialhe restaurar com mais liberdade os seus quadros e estreitar a sua ligação com a Santa Sé.” (JESUS, 1993, p. 68-78)

A partir da celebração do Concílio Plenário Latino-americano, em Roma no ano de 1898, nas primeiras décadas do século XX o Episcopado brasileiro reforça a importância da Escola Católica e confirma o domínio da Santa Sé nas Igrejas vindas do colonialismo ibérico e claro, isso trouxe consequências para a escola pública, pois a Igreja Católica desaprovava escolas neutras, mistas e leigas, suprimindo o ensino da doutrina cristã. Foram muitas idas e vindas nas questões que buscavam o espaço para uma educação na fé e na crença respeitando o ser humano e com uma intenção e um objetivo sem interesses alheios ao que o cristão tem como missão.

Aconteceram muitas mudanças na educação que vieram como reação ao pensamento republicano. E no mandato do Ministro Benjamim Constant foi que houve reforma no ensino, com alterações no currículo, conforme critérios de Augusto Comte. E nessa época o governo da República passou a prestou atenção na Educação colocando-a, "a serviço de interesses econômicos, sem preocupação com o pluralismo, ou com a experiência cultural do povo brasileiro." (MOTTA, 1997, p.111-113) Os Bispos então "afirmavam que para os crentes, independente da confissão, a indiferença religiosa seria muito negativa, uma vez que o ensino leigo seria o mesmo que ateu e irreligioso, e, para eles, esta configuração para educação seria responsável por profundos males ao país.” (NERY, 1993, p.88)

Ao finalizar o século XIX surgiu uma fase de crescimento com o surgimento de novas classes sociais, fruto das migrações internas, provocando mudanças na urbanização do país, por conta do enorme crescimento demográfico. Muitas foram as estratégias que permitiram a ICAR fazer acontecer aos poucos a realização da sua missão, em especial na área da educação. A ICAR agiu na ação política por meio da Liga Eleitoral Católica (LEC), dos Círculos Operários Católicos e da Juventude Católica (Universitária - Estudantil - Operária). E a partir do princípio da separação Estado e Igreja, a educação por questões de laicidade, sofreu a ausência das religiões. 
Mais tarde, um projeto de Ruy Barbosa, possibilitando que o Ensino Religioso nas escolas ocorresse fora das aulas e com professores leigos indicados por tradições religiosas, foi uma espécie de apoio para a ICAR. “[...] 1. O ensinar religioso será dado pelos ministros de cada culto, no edifício escolar, se assim o requererem os alunos, cujos pais, o desejam, declarando-o ao professor, em horas que regularmente se determinarão sempre posteriores às da aula," (BARBOSA, 1947, p.70-72) O Ensino Religioso tem seu conflito a partir da República, quando da definição de que deveria ser ensino leigo, não mais tutelado por tradições religiosas.

Em 1928 o Governador de Minas Gerais, Antônio Carlos, promulgou a Lei n. 1092/28 (MATOS, 1996, p.46-47) re-introduzindo o Ensino Religioso nas escolas oficias de Minas Gerais, a fim de amenizar a revolta dos católicos por conta das medidas laicizante no sistema escolar. O clero de Minas com a sociedade viu o reconhecimento do governo, em relação ao empenho da ICAR e como ajudou na solução dos problemas sociais amenizando os conflitos e ajudando o Estado no que se refere ao bem da população. A busca do catolicismo na sociedade brasileira é fundamentada na crença de que somente com a aproximação da verdadeira finalidade que é o Criador, se possibilita a concepção de sociedade e que a integralidade é realmente fundamental para o desenvolvimento das pessoas.

A educação foi vista como uma estratégia para o desenvolvimento de conceitos, que pela sua "mediação seria possível infundir hábitos morais pelo governo da vontade, a fim de colocar o homem em sua própria natureza ministrando conhecimento moral e religioso, elevando a sua personalidade individual e social, pela união com Deus.” (CURY, 1988, p.114115) Em todos os momentos em que havia articulação na área política havia também muita preocupação com o andamento da educação, pois ainda não era possível organizar um espaço para escolas principalmente dos anos iniciais. Em um contexto de mudanças constantes na sociedade, o Ensino Religioso se mantinha em uma linha liberal na escola pública e com frequência opcional para o aluno, com a finalidade de estabelecer um modelo estritamente confessional.

Os católicos brasileiros que não eram a favor a laicização da escola oficial, manifestaram-se, dizendo tratar-se de injusta imposição à população brasileira, cuja maioria confessa a religião católica. "Ao longo dos anos desenvolveu-se uma intensa campanha para reduzir os efeitos práticos desse dispositivo constitucional, assim como se tornou uma questão central para a Igreja da época o tema do Ensino Religioso, além da escola confessional" (MATOS, 1996, p. 59-61) 
A Igreja sempre foi contrária ao processo de laicização e a República trouxe a esperança de se organizar no Brasil uma rede pública de ensino para todos, mas somente com a "Revolução de Trinta e a radicalização das discussões políticas, conseguiu-se responsabilizar o Estado, por meio da Constituição de 1934, pelo estabelecimento de um Plano Nacional de Educação e a expansão da rede de ensino.” (NEMI, 1996, p.16)

O governo percebe a Igreja como força indispensável ao processo político e nos anos de 1910 a 1930 houve grande esforço de aproximação entre a Igreja Católica, como instituição, e o governo. "A mudança na linguagem do episcopado e de seus gestos concretos de mobilização de massas, como por exemplo, o Congresso Eucarístico Nacional do Rio de Janeiro, por ocasião do centenário da Independência do Brasil, em 1922.” (LUSTOSA, 1991, p.20-37)

O Presidente Getúlio Vargas tinha interesse no apoio da Igreja como aliada para governar o país e então haveria o almejado reconhecimento oficial da Igreja Católica pelo Estado e, portanto, admite o Ensino Religioso na escola, baseado no Pacto Lateranense, de 1929. E na década de 1930, Augusto de Lima defende a ICAR assim como também Leonel Franca interferindo com o texto sobre o Ensino Religioso de Minas Gerais, para a Constituição de 1934. "A Constituição de 16 de julho de 1934 tornara obrigatória a inclusão do Ensino Religioso no horário escolar, mantendo facultativa a frequência.” (NERY, 1993, p.88)

Educadores da Escola Nova educadores liberais que reagiram e entraram em confronto com a Igreja, pois tinham o objetivo de tornar o ensino laico desvinculado da religião e as lideranças da Igreja queriam a implementação do pensamento da Igreja católica na educação, o que foi reforçado pela encíclica "Divini Illius Magistri”, de Pio XI, divulgada em 1929, que considerava "a escola como instituição subsidiária e complementar da família e da Igreja" (FIGUEIREDO, 1995, p.45-53)

Havia argumentos fortes para manter o ensino da religião católica nas escolas, inclusive reforçando que este era um parâmetro para se obter a paz social. Por outro lado, quem apoiava a laicidade da educação não admitia que o Estado, financiando a religião, pudesse estar tendo uma postura democrática. $\mathrm{O}$ que se defendia também era o bloqueio ao proselitismo principalmente no interior do Brasil, pois as práticas religiosas, segundo eles se confundiam com fetichismo. Temas do Ensino Religioso, como também do papel do Estado na fixação do "Plano Nacional de Educação foram os mais discutidos, assim como a questão da gratuidade e a colaboração recíproca entre Igreja e Estado, e a livre iniciativa nas escolas particulares.” (CURY, 1988, p.114-115) 
Entre os anos de 1937 e 1945, com o Estado Novo começa uma fase nova no regime político do Brasil e com o Golpe de Estado, em novembro de 1937 veio a nova Constituição, com a perda de dispositivos da Igreja, voltando a posição da Constituição de 1891 que trás o contexto político em confronto entre a posição católica e a posição liberal, que vinham dos princípios filosóficos relacionados com a concepção vigente de Educação. (FONAPER, 1998)

Em 1941 Gustavo Capanema preparou a Lei Orgânica do Ensino Médio incluindo a instrução religiosa no currículo das disciplinas de educação geral. A versão final da Lei Orgânica diz que o ensino da religião deve fazer integrar a educação da adolescência, portanto os estabelecimentos secundários devem, no primeiro e segundo ciclo, serem incluídos programas de religião e fixados pela autoridade eclesiástica o regime didático. (REPÚBLICA DOS ESTADOS UNIDOS DO BRASIL, 1942) Na Constituição de 1946, Gustavo Capanema propôs que na legislação, o ensino religioso deve constituir disciplina de horários oficiais, com matrícula facultativa e ministrada de acordo com a confissão religiosa do aluno ou do seu responsável legal. (BRASIL, 1946)

Durante aproximadamente quinze anos discutido amplamente a educação e o Ensino Religioso, a Igreja Católica sentiu a necessidade de novas maneiras de diálogo entre a sociedade e a Igreja. Nessa ocasião é que foi fundada a Conferência Nacional dos Bispos do Brasil (CNBB) na cidade do Rio de Janeiro no dia 14 de outubro de 1952. A partir da criação da CNBB o tema Ensino Religioso recebe atenção especial dos Bispos que acompanham as Leis e as discussões a respeito da disciplina. Houve nesse tempo muitas polêmicas em relação ao conteúdo e a metodologia adotada para a disciplina, pois o momento político que vivia o Brasil durante a ditadura, não era propício para algumas iniciativas. Inúmeras vezes a metodologia era vista como comunista e os autores de determinados livros didáticos foram inclusive presos e torturados e seus livros foram recolhidos. Houve na época muitas situações em que os religiosos precisavam ser muito corajosos, a fim de levar a evangelização ao povo desta nação.

O Brasil se fortalece com a religiosidade plural, pois a opção religiosa muitas vezes vem da experiência e da busca pessoal, junto à comunidade onde há a possibilidade de conhecimento e conscientização dos conceitos e valores humanos. (CNBB, 1991) A atuação da ICAR na história do Brasil foi muito efetiva em relação ao compromisso com o Ensino Religioso, sempre respeitando a legislação e as mudanças na sociedade e lutando para que a missão evangelizadora tivesse a eficácia merecida. Um ato importante nesse cenário é o Acordo entre o governo da República Federativa do Brasil e a Santa Sé: “A República Federativa do Brasil, em observância ao direito de liberdade religiosa, da diversidade cultural e da pluralidade confessional do País, 
respeita a importância do ensino religioso em vista da formação integral da pessoa." ([REPÚBLICA FEDERATIVA DO BRASIL, Decreto nº 7.107 de 11 de Fevereiro de 2010, Art. 11) No documento é garantido ao estudante o respeito à diversidade cultural religiosa: "assegurado o respeito à diversidade cultural religiosa do Brasil, em conformidade com a Constituição e as outras leis vigentes, sem qualquer forma de discriminação." (REPÚBLICA FEDERATIVA DO BRASIL, Decreto no 7.107 de 11 de Fevereiro de 2010, Art. 11)

Junqueira escreve sobre o envolvimento eclesiástico nas questões do Ensino Religioso enfatizando que o processo histórico melhor documentado certamente é o da Igreja Católica, o Episcopado e os assessores que participaram da articulação política com a finalidade de alterar situações criadas. (JUNQUEIRA, 2000)

As considerações feitas por meio de documentos da CNBB destacam que o Ensino Religioso é área de conhecimento, que segue as leis da nação e respeita o órgão responsável pelo estabelecimento das diretrizes para essa disciplina e pela preparação dos seus profissionais. Assim, o ensino religioso procura dialogar enquanto aprofunda, desenvolve e também potencializa a ação de educar. (CONGREGAÇÃO PARA O CLERO, 1998)

A CNBB respeita o ambiente escolar e leva em conta a realidade, a diversidade e o pluralismo religioso na realidade da sociedade. (CNBB, 1983) Como órgão representativo da Igreja, a CNBB tem a proposta de ser para o ensino religioso no Brasil, um espaço de atendimento permanente, assessoria, atualização, pesquisa e acompanhamento, a fim de seguir rigorosamente o projeto de Jesus Cristo para a humanidade, considerando as leis vigentes no país e lutando para que a dignidade de cada ser humano seja respeitada.

\section{O Supremo Tribunal Federal e o Ensino Confessional}

No dia 27 de setembro de 2017 acontece uma decisão importantíssima para o Ensino Religioso no Brasil. O Plenário do Supremo Tribunal Federal declara constitucional o Ensino Religioso Confessional na rede pública de ensino no Brasil. Ao prever a facultatividade da matrícula na disciplina, a Constituição Federal resguardou a laicidade do Estado e a liberdade de crença da população. Assim foi entendido que desnecessário alterar a interpretação vigente da Constituição.

A PGR pedia a interpretação em conformidade com a Constituição Federal ao dispositivo da Lei de Diretrizes e Bases da Educação - LDB (caput e parágrafos $1^{\circ}$ e $2^{\circ}$, do artigo 33, da Lei 9.394/1996) e ao artigo 11, parágrafo $1^{\circ}$ do acordo firmado entre o Brasil e a Santa Sé (promulgado por meio do Decreto 7.107/2010) e que o ensino religioso nas escolas 
públicas se desvinculasse de religião específica, portanto até a contratação de professores deveria ter essa característica e a disciplina ensinada sob uma perspectiva laica.

A característica não confessional é de que o ensino religioso tem neutralidade. E o confessional, caracteriza-se por confissões explicitas. O interconfessional ensina valores e práticas religiosas com base em elementos comuns entre os credos.

A decisão foi pela improcedência da ação direta de inconstitucionalidade proposta pela PGR. Na verdade, o fato de ser a matrícula facultativa, não causa constrangimentos aos que não professam a religião predominante. Nas palavras de Cármen Lúcia, na época presidente do STF a laicidade do Estado: "está respeitada e não vejo contrariedade que me leve a declarar inconstitucional, as normas questionadas [...] A lei questionada não autoriza proselitismo, catecismo ou imposição de uma religião específica." (ROCHA, Pronunciamento sobre o Ensino Religioso no Brasil, em 17 de setembro de 2019)

Certamente ainda serão muitos os desafios a serem enfrentados por todos os envolvidos no processo do Ensino Religioso no Brasil, mas são pessoas corajosas e cheias de esperança, envolvidas nesse processo e, portanto, as decisões serão também de acordo com o que representa o correto direcionamento para as instituições e seus educandos.

\section{Considerações finais}

A história do Brasil na área educacional mostra como foi e continua sendo valiosa a contribuição da Igreja Católica Apostólica Romana (ICAR), muitas vezes adaptando-se às situações, de acordo com as orientações da Santa Sé, as leis da sociedade, leis da Igreja e do Estado brasileiro. As constantes e rápidas transformações da sociedade exigem muito dos cristãos de uma forma geral e a Igreja Católica Apostólica Romana está constantemente adaptando-se às novas exigências da sociedade com segurança, equilíbrio e discernimento.

Desde o início da história do Brasil a Igreja procurou acompanhar a humanidade em suas novas formas de compreender o mundo. Procurou também oferecer amplo repertório de conhecimentos, proporcionando experiências dentro de cada realidade e fazendo com que a resposta a cada situação atendesse a grande maioria desses anseios, para o pleno e harmônico desenvolvimento humano, compromisso da missão do Ensino Religioso e da ICAR em especial. Na realidade de hoje a Igreja Católica Apostólica Romana reúne as habilidades necessárias para lidar com essas transformações, sem perder a essência da Religião Católica e ainda agrega valores aos segmentos da sociedade que passam por transformações significativas mostrando a visão do projeto de Jesus Cristo para a humanidade. 


\section{Referências}

BARBOSA, Textos de Rui Barbosa. Campanhas Presidenciais, Vol. VII, 70-72. São Paulo, Iracema, 1965.

BARBOSA, Obras completas, Vol. X, 71-73. Rio de Janeiro, Ministério da Educação e Saúde, 1947.

BLOCH, Marc Leopold Benjaminz. A Sociedade Feudal. 2. ed. Lisboa: Edições 70, 1987.

BONAVIDES, R. AMARAL. IMPÉRIO DO BRASIL, Constituição Política do Império do Brasil (25 março 1824), in: P. BONAVIDES; R. AMARAL, Textos Políticos da História do Brasil, Vol. VIII, Brasília, Senado Federal, 1996, 123.

BONAVIDES - R. AMARAL. IMPÉRIO DO BRASIL, Documentos complementares do Império do Brasil (15 outubro 1827), in: P. BONAVIDES - R. AMARAL, Textos Políticos da História do Brasil, Vol. I, Brasília, Senado Federal, 1996, 142)

BONAVIDES - R. AMARAL. REPÚBLICA DOS ESTADOS UNIDOS DO BRASIL, Constituição da República dos Estados Unidos do Brasil, 24 fevereiro 1891, in: P. BONAVIDES - R. AMARAL, Textos Políticos da História do Brasil, Vol. VIII, 193. Brasília, Senado Federal, 1996.

BONAVIDES - R. AMARAL. REPÚBLICA DOS ESTADOS UNIDOS DO BRASIL, Constituição dos Estados Unidos do Brasil, 18 setembro 1946, in: P. BONAVIDES - R. AMARAL, Textos Políticos da História do Brasil, Vol. IX, Brasília, Senado Federal, 286, 1996. CHIZZOTTI, Antonio. Pesquisa em ciências humanas e sociais, p. 79 São Paulo: Cortez, 2003.

CONFERÊNCIA NACIONAL DOS BISPOS DO BRASIL, A Igreja Católica diante do pluralismo religioso no Brasil - I (Estudo n. 62), 115-116. São Paulo, Paulinas, 1991.

CONFERÊNCIA NACIONAL DOS BISPOS DO BRASIL, CNBB, Catequese Renovada, 1983.

CONFERÊNCIA NACIONAL DOS BISPOS DO BRASIL, Coletânea dos Pronunciamentos da CNBB 1988 a 1992. Brasília: CNBB, 1988.

CONGREGAÇÃO PARA O CLERO, Diretório Geral para a Catequese, n. 73. São Paulo, Paulinas, 1998.

CURY, C. Ideologia e educação brasileira - católicos e liberais 114-115. São Paulo, Cortez, 4a. ed. 1988.

FIGUEIREDO, A. Ensino Religioso, perspectivas pedagógicas, 45-46; 45-53. Petrópolis, Vozes, 1995.

FONAPER, FÓRUM NACIONAL PERMANTE DO ENSINO RELIGOSO. Parâmetros Curriculares Nacionais do Ensino Religioso, 12. São Paulo: Ave Maria, 3a . ed, 1998. 
FONAPER, FÓRUM NACIONAL PERMANTE DO ENSINO RELIGOSO. Parâmetros Curriculares Nacionais do Ensino Religioso, 14-15. São Paulo: Ave Maria, 3a . ed, 1998.

JESUS, J. O Ensino Religioso escolar na Itália fascista e no Brasil (1930-45), 68, in: "Educação em Revista", v.17, p. 68-78, 1993.

JUNQUEIRA, S. O Ensino Religioso no Brasil: estudo do seu processo de escolarização. Roma: UPS, 2000.

JUNQUEIRA, S.; WAGNER R. Organizadores. O Ensino Religioso no Brasil, Ed. PUCPR, Champagnat, Curitiba, 2011.

LUSTOSA, O. A Igreja Católica no Brasil República, 20-37. São Paulo, Paulinas, 1991.

MATOS, H. Caminhando pela História da Igreja, 59-61, Vol. III, Belo Horizonte, Lutador, 1996.

MATOS, H. Caminhando pela História da Igreja, 46-47, Vol. III, Belo Horizonte, Lutador, 1996.

MOTTA, E. Direito Educacional e educação no século XXI, 111-113. Brasília, UNESCO, 1997.

NEMI, A; MARTINS, J (orgs.). Didática de História - O tempo Vivido: Uma outra História? Conteúdo e Metodologia - $1^{\text {a a }} 4^{\text {a }}$ Série - História.São Paulo, SP: Editora FTD, 1996.

NEMI, A; MARTINS, J. Uma outra história ? O tempo vivido, 16. São Paulo, FTD, 1996.

NERY, I. O Ensino Religioso Escolar no Brasil (ERE) no contexto da história e das leis, 10 11, in: "Revista de Educação AEC" v.22, p. 88, 1993.

NERY, I. O Ensino Religioso Escolar no Brasil (ERE) no contexto da história e das leis, in: "Revista de Educação AEC" v.22, p. 12, 1993.

REPÚBliCA DOS ESTADOS UNIDOS DO BRASIL, Portaria Ministerial n. 97, 22 abril 1942, 25. Rio de Janeiro, Ministério da Educação e Ensino, 1942.

REPÚBliCA FEDERATIVA DO BRASIL. Acordo Estado do Vaticano e Governo Brasileiro. Brasília: Presidência da República, 2010.

ROCHA, CÁRMEN LÚCIA ANTUNES. Presidente do STF, Pronunciamento sobre o Ensino Religioso no Brasil. 17 de setembro de 2019.

STEIL, C. O Ensino Religioso na sociedade plural, in: “Diálogo”, 48-49, 1996. 